\title{
Neonatal Infection among Women with Prior Premature Labor
}

\author{
Tandu-Umba Barthélémy*, Kalonji Tshianyi David \\ Department of Obstetrics and Gynecology, University Clinics, Kinshasa, DR Congo \\ Email: "btanduumba@yahoo.fr
}

Received 13 November 2015; accepted 5 December 2015; published 8 December 2015

Copyright (C) 2015 by authors and Scientific Research Publishing Inc.

This work is licensed under the Creative Commons Attribution International License (CC BY). http://creativecommons.org/licenses/by/4.0/

(c) $\underset{\mathrm{EY}}{\mathrm{i}}$ Open Access

\section{Abstract}

Objectives: Since studies demonstrate that neonates born to mothers having been cared for premature labor will suffer from congenital neonatal sepsis, we aimed to evaluate the prevalence and main risk factors of neonatal infection among mothers having experienced a prior premature labor. Methods: This was a cross sectional study carried out from January 1st throughout 31st December, 2013 at the university clinics of Kinshasa. It concerned all delivered women at term having been cared for premature labor prior to giving birth a live newborn. Maternal variables of interest were: parity, gestation, age, intrapartum fever, malaria, urogenital infection during the last 2 weeks before delivery (UGI), premature rupture of membranes (PROM), cervical cerclage, meconium-stained amniotic fluid (MSAF) and the way of delivery. For neonates attention was paid on gestational age, birth weight, admission at neonatal intensive care unit (ANICU) and infection as stated within three days after birth. T-test and Chi-square were used where appropriate. Logistic analysis was used to determine the risk for maternal variables to induce neonatal infection (OR and $\mathrm{CI}$ ), the significance stated at $\boldsymbol{p}<\mathbf{0 . 0 5}$. Results: Fifty two mother-infant couples were recruited. of these 19 neonates were infected (prevalence of $36.5 \%$ ). Mean age, gestational age and birth weight were $30.19 \pm 5.32$ years, $37.2 \pm 2$ weeks and $2638 \pm 588 \mathrm{~g}$, respectively. Infected neonates had their gestational age and birth weight significantly lower whilst proportion of ANICU higher than that on non infected. Prematurity, PROM, UGI, prior cerclage and MSAF were significantly more frequent in couples with neonatal infection. Prematurity, birth weight $<2500 \mathrm{~g}$ and UGI were found to enhance the risk by 3 to 4 times. Conclusion: The prevalence of neonatal infection was very high. Prematurity, birth weight $<2500 \mathrm{~g}$ and maternal UGI were found to enhance the risk by 3 to 4 times.

\section{Keywords}

Prior Premature Labor, Maternal Urogenital Infection, Neonatal Infection, Risk Factors

\footnotetext{
${ }^{*}$ Corresponding author.
} 


\section{Introduction}

Premature labor/delivery is one of the five common conditions (including premature rupture of membranes (PROM), small for gestational age, congenital anomalies and pregnancy induced-hypertension) defining the so called "Great Obstetrical Syndromes" [1]. In average 50\% of cases, it ends into preterm birth that is now the leading cause of neonatal death and the second leading cause of childhood death globally [1] [2]. The main risk factors for premature labor include socioeconomic, psychological (stress) and environmental ones, whilst actual etiologies are dominated by pathological situations such as parasitic (e.g. malaria) infestation, urinary tract and vaginal/genital infections and cervical shortening [1]-[4].

Studies demonstrate that up to $37 \%$ of neonates born to mothers having been cared for premature labor (even with unruptured membranes) will suffer from congenital neonatal sepsis, also called early-onset sepsis (within 2 - 3 days of birth) [3]-[7]. In comparison with environmental (nosocomial) neonatal sepsis (later-onset infection), such a maternally acquired infection progresses more rapidly and carries a higher mortality [8]-[10]. Although PROM (either preterm or $\geq 37$ weeks' gestation) and duration of rupture of membranes $\geq 18$ - 24 hours are assumed to worsen the situation, premature labor in itself thus appears to be linked to neonatal sepsis. The latter might be linked to histological chorioamniotitis and microbial footprints in the amniotic cavity that were found in patients at risk of PROM [1] [2] [11]. Meanwhile, before much is known on the causative relationships between maternal exposure before PROM and neonatal condition, authors agree that efforts are to be orientated on prevalent risk factors according to different environments in order to properly base an antibiotic prophylaxis [8]-[10] [12]. This is mostly expected in areas such as sub-Saharan countries where neonatal sepsis, although hugely contributing to the burden of neonatal morbidity and mortality [12] [13], has never been addressed this way.

Based on maternal risk factors Mukhopadhyay and Puopolo [8] and Puopolo et al. [9] estimated the probability of neonatal early-onset infection in order to reduce the number of uninfected neonates to be provided with antibiotic prophylaxis. Their predictive model, however, focused on features (group B streptococcus, delivery at $\leq 34$ weeks' gestation, long duration rupture of membranes, maternal fever) not suitable for cases where fetal membranes are unruptured. So, the question seems ongoing.

The present study was intended to evaluate the prevalence as well as the main risk factors of neonatal infection among mothers having experienced a prior (threatened) premature labor long before delivery.

\section{Methods}

This was a cross sectional study covering one year (January 1st till 31st December, 2013) at the university clinics of Kinshasa, DR Congo. It concerned all women having been cared for premature labor prior to giving birth and having delivered of a live newborn at the maternity unit of the department of obstetrics and gynecology, university clinics of Kinshasa. Prior threatened preterm labor was stated at gestational age less than 37 weeks as the presence of at least 3 uterine contractions in 10 minutes and cervical changes (effacement and or dilation greater than $1 \mathrm{~cm}$ ) in women with intact fetal membranes. Maternal variables of interest were: parity, gravidity, gestational age, cervical cerclage, birth delay under tocolysis, intrapartum fever, malaria, urogenital infection during the last 2 weeks before delivery (UGI), premature rupture of membranes (PROM) and the way of delivery. For neonates attention was paid on gestational age, meconium-stained amniotic fluid, birth weight, admission at neonatal intensive care unit (NICU). Neonatal infection was stated within three days after birth by the staff of the neonatal unit, based on general (fever or hypothermia, cyanosis), respiratory (apnea, respiratory distress), neurologic and laboratory (NFS, CRP, Hemoculture) signs. Data were registered using Microsoft Excel (Microsoft Corporation, 86. Redmond, WA, USA, 2007). After transfer to SPSS (version 18.0; SPSS Inc., Chicago, IL, USA) for statistical calculations, we sought to evaluate the relationship of specific pre- and intrapartum factors to occurrence of neonatal infection. T-test/Mann-Whitney and Chi-square/Fischer test were used where appropriate to compare means and proportions. Logistic analysis was used to determine the risk for each significant maternal variable to induce neonatal infection (OR and CI), the significance stated at $\mathrm{p}<0.05$.

\section{Results}

During the study period the delivery count was 783, whilst 70 admissions for premature labor were registered. Of these, 18 were excluded because of incomplete files mostly in relation with neonatal status, leaving 52 mother- 
infant couples that were recruited. In total 19 neonates were recognized with sepsis (a prevalence of 36.5\%). Mean maternal age, gestational age and birth weight of the whole study sample were $30.19 \pm 5.32$ years, $37.2 \pm 2$ weeks and $2638 \pm 588 \mathrm{~g}$, respectively. The mean duration of birth delay under tocolysis was 18 days. We found no significant differences between couples with and without neonatal infection as of maternal age, parity, gravidity, abortus status and birth delay under tocolysis. Other general characteristics are summarized in Table 1 . Women had no group B streptococcus status.

Gestational age and birth weight of infected neonates were significantly lower than that of non infected, whilst their proportion of meconium stained amniotic fluid and ANICU was steadily higher. So, $<37$ week gestational age, amniotic fluid status and birth weight $<2500$ g were included among other traditional risk factors for neonatal infection in an univariate analysis aimed to determine their association with the occurrence of neonatal infection in a dichotomic mode (having the risk factor or not). We observed (Table 2) that variables found significantly more frequent in mother-infant couples with neonatal infection were: prematurity, PROM, maternal UGI, prior cerclage and stained amniotic fluid. However, prematurity, birth weight $<2500 \mathrm{~g}$ and maternal UGI were the only ones found to enhance the risk of neonatal infection 3- to 4-fold.

\section{Discussion}

In our study the prevalence of neonatal infection was $36.5 \%$. This is similar to that reported by other authors among neonates born to mothers having been cared for threatened premature labor [3]-[7]. This is much higher when considering the overall incidence of possible severe neonatal bacterial infection of $7.6 \%$ reported by Seale et al. [13] in their systematic review and meta-analysis (excluding very preterm neonates) in sub-Saharan Africa, south Asia, and Latin America for 2012 (only 3 African countries included: Ghana, Kenya and Zambia). This means that, irrespective of the status of fetal membranes, preterm labor carries an actual risk of neonatal infection. Indeed, although PROM, a well known risk factor for neonatal sepsis, was significantly more frequent in case of neonatal infection, it did not range among the only 3 features found to steadily enhance that risk: maternal urogenital infection, birth weight $<2500 \mathrm{~g}$ and prematurity (corresponding to failure of conservative treatment).

Table 1. Maternal and neonatal general characteristics of the study sample (means/\%).

\begin{tabular}{|c|c|c|c|c|}
\hline & Overall & $\begin{array}{c}\text { NNI+ } \\
(\mathrm{N}=19)\end{array}$ & $\begin{array}{c}\mathrm{NNI}^{-} \\
(\mathrm{N}=33)\end{array}$ & $\mathrm{p}$ \\
\hline Maternal variables & Mean \pm SD & Mean \pm SD & Mean \pm SD & \\
\hline Age (years) & $30.19 \pm 5.32$ & $30.16 \pm 5.21$ & $30.22 \pm 5.43$ & - \\
\hline Parity & $1.94 \pm 0.3$ & $1.93 \pm 0.3$ & $1.94 \pm 0.4$ & - \\
\hline Gravidity & $2.9 \pm 0.7$ & $2.9 \pm 0.8$ & $2.9 \pm 0.5$ & - \\
\hline Abortus & 1.0 & 1.0 & 1.0 & - \\
\hline Birth delay under tocolysis (days) & $18.3 \pm 3.3$ & $18.2 \pm 4.2$ & $18.3 \pm 3.5$ & - \\
\hline Neonatal variables & $\begin{array}{c}\text { Mean } \pm \text { SD } \\
\text { N (\%) }\end{array}$ & $\begin{array}{c}\text { Mean } \pm \text { SD } \\
\text { N (\%) }\end{array}$ & $\begin{array}{c}\text { Mean } \pm \text { SD } \\
\text { N (\%) }\end{array}$ & \\
\hline Gestational age (weeks) & $37.1 \pm 2.0$ & $36.2 \pm 2.2$ & $37.7 \pm 1.8$ & $0.012^{*}$ \\
\hline Birth weight (g) & $2638 \pm 588$ & $2255 \pm 562$ & $2859 \pm 485$ & $0.000^{*}$ \\
\hline \multicolumn{5}{|l|}{ Sex } \\
\hline Male & $24(46.2 \%)$ & $9(47.4 \%)$ & $15(45.5 \%)$ & $0.894^{\text {*⿻ }}$ \\
\hline Female & 28 (53.8\%) & $10(52.6 \%)$ & 18 (54.5\%) & \\
\hline \multicolumn{5}{|l|}{ Admission at NICU } \\
\hline Yes & $12(23.1 \%)$ & $9(47.4 \%)$ & $3(9.1 \%)$ & $0.004^{* *}$ \\
\hline No & $40(76.9 \%)$ & $10(52.6 \%)$ & 30 (90.9\%) & \\
\hline
\end{tabular}

${ }^{*}$ Mann Whitney; ${ }^{* *}$ Chi-square or Fischer's exact test; Legend: NNI+ = Neonatal infection; NNI- = Without neonatal infection. 
Table 2. Association of maternal variables with neonatal infection.

\begin{tabular}{|c|c|c|c|c|c|c|}
\hline & $\begin{array}{l}\text { Whole sample } \\
\qquad \begin{array}{c}(\mathrm{n}=52) \\
\mathbf{N}(\%)\end{array}\end{array}$ & $\begin{array}{c}\text { NNI+ } \\
(\mathrm{n}=19) \\
\mathbf{N}(\%)\end{array}$ & $\begin{array}{c}\text { NNI- } \\
(\mathrm{n}=33) \\
\mathbf{N}(\%)\end{array}$ & $\mathrm{p}$ & OR & CI \\
\hline \multicolumn{7}{|l|}{ Gestational age } \\
\hline$<37$ weeks & $17(32.7)$ & $12(63.2)$ & $5(15.2)$ & 0.001 & 3.53 & $1.70-7.33$ \\
\hline$\geq 37$ weeks & 35 (68.6) & $7(36.8)$ & $28(84.8)$ & & & \\
\hline \multicolumn{7}{|l|}{ Birth weight } \\
\hline$<2500 \mathrm{~g}$ & 19 (36.5) & $10(52.6)$ & $9(27.3)$ & 0.004 & 3.43 & $1.56-6.22$ \\
\hline$\geq 2500 \mathrm{~g}$ & $33(63.5)$ & $9(47.4)$ & $24(72.7)$ & & & \\
\hline \multicolumn{7}{|l|}{ Intrapartum fever } \\
\hline Yes & $5(9.6)$ & $2(10.5)$ & $3(9.1)$ & 0.876 & 1.18 & $0.18-7.75$ \\
\hline No & 47 (90.4) & 17 (89.5) & 30 (90.9) & & & \\
\hline \multicolumn{7}{|l|}{ Malaria } \\
\hline Yes & $29(55.8)$ & $10(52.6)$ & $19(57.6)$ & 0.730 & 0.82 & $0.26-2.55$ \\
\hline No & $23(44.2)$ & $9(47.4)$ & $14(42.4)$ & & & \\
\hline \multicolumn{7}{|l|}{ PROM } \\
\hline Yes & $8(15.4)$ & $8(42.1)$ & $0(0.0)$ & 0.000 & 0.25 & $0.15-0.42$ \\
\hline No & $44(84.6)$ & $11(57.9)$ & $33(100.0)$ & & & \\
\hline \multicolumn{7}{|l|}{ UGI } \\
\hline Yes & $16(30.8)$ & $9(47.4)$ & $7(21.2)$ & 0.049 & 3.34 & $1.0-11.41$ \\
\hline No & $36(69.2)$ & $10(52.6)$ & 26 (78.8) & & & \\
\hline \multicolumn{7}{|c|}{ Aspect of amniotic fluid } \\
\hline Clear & 47 (90.4) & $14(73.7)$ & $33(100.0)$ & 0.009 & 0.30 & $0.19-0.46$ \\
\hline Meconium & $5(9.6)$ & $5(26.3)$ & $0(0.0)$ & & & \\
\hline \multicolumn{7}{|l|}{ Cerclage } \\
\hline Yes & $5(9.6)$ & $4(21.1)$ & $1(3.0)$ & 0.034 & 0.40 & $0.22-0.73$ \\
\hline No & 47 (90.4) & 15 (78.9) & $32(97.0)$ & & & \\
\hline \multicolumn{7}{|l|}{ Way of delivery } \\
\hline Vaginal & 25 (48.1) & $7(36.8)$ & $18(54.5)$ & 0.219 & 2.10 & $0.65-6.54$ \\
\hline Cesarean section & 27 (51.9) & $12(63.2)$ & $15(45.5)$ & & & \\
\hline
\end{tabular}

Legend: $\mathrm{NNI}+=$ neonatal infection; $\mathrm{NNI}-=$ without neonatal infection .

Chan et al. [12] recently published a systematic review and meta-analysis of 122 articles (only 3 from Africa) to estimate the prevalence of early-onset neonatal infection in cases where the pregnant woman was infected or colonized with bacterial pathogens. Signs of maternal infection were: intrapartum maternal fever, uterine tenderness, maternal tachycardia, malodorous vaginal discharge, elevated white cell count and elevated c-reactive protein. Obviously, these are signs of chorioamniotitis, mostly after rupture of membranes of long duration ( $>18$ hours), making it understandable the transversal (mother-infant) transmission. In case of preterm labor such as in our series where there is no sign/proof of infected ovum, it remains difficult to link uterine activity long before delivery to neonatal infection. Indeed, in our series, intrapartum fever had no significant link with occurrence of 
neonatal infection, probably due to particular environment of our setting where prior origin of fever is malaria. Yet, the need remains to find relevant features likely to guide any decision of intrapartum antibiotherapy aimed to decrease the risk of neonatal infection [8]. Authors insist on the fact that empiric antibiotherapy should not be administered systematically [11] [12], since routine use is associated with outbreaks of resistant organisms.

The connection of (threatened) premature labor with intra-amniotic or neonatal infection even long before rupture of membranes might be found in maternal-infant transfer of inflammatory markers that has been demonstrated in case of maternal infection/inflammation [14]. So, unrecognized chorioamniotitis and inflammatory markers might mediate both uterine contractions and fetal/neonatal infection/inflammation [1] [2] [4]. Premature labor can thus be considered as a clinical manifestation of a long lasting intraamniotic/fetal infection [1] [2] [15] [16]. Therefore, any tocolysis tempting to prevent further preterm contractions is expected to prolong the duration of a pathophysiological situation likely to raise the risk of neonatal sepsis.

Criteria of premature onset of labor to be considered as either risk or causative factor of neonatal infection can be derived from clinical and laboratory features such as: detection of fetal fibronectin from cervicovaginal secretions after 24 weeks of gestation, cervical shortening attested by transvaginal ultrasonography, bacterial vaginosis, and elevated levels of interleukin (IL-6, IL-8), ferritin and granulocyte colony-stimulating factor [17]. However, due to usual absence of adequate equipment for assessment of all these conditions, prior threatened premature labor should be systematically regarded as heralding neonatal infection. Our data showed preterm delivery to be an additional factor significantly associated with neonatal infection, meaning that the attempt to block uterine contractions failed. We thus hypothesize that the risk for fetal/neonatal infection is minored in cases of successful conservative treatment. This remains to be addressed in order to properly base an empiric antibacterial treatment option [10].

Our study identified women with three components (maternal unrecognized infection, preterm labor and early-onset neonatal infection) that seem to be connected with each other. Although early-onset neonatal infection has been recognized as a consequence of prior preterm labor, authors have most focused on condition after rupture of membranes. So, the question of cases where membranes are intact is rarely addressed. Taking in account local environmental exposure, our study makes it possible to restrict the number of women and neonates to be provided with antibiotic prophylaxis to cases of unsuccessful conservative treatment.

Some weaknesses are to be mentioned in our study. Neonatal sepsis is most caused by E.coli, coagulase negative staphylococcus, microorganisms from the normal flora of the maternal vaginal tract, including group B streptococci, Hemophilus influenzae, Listeria monocytogenes, and Streptococcus pneumonia. So, due to lack of reproductive tract/genital bacterial and neonatal cultures to attest maternal/neonatal colonization, this study cannot lead to specific local option to efficiently protect both mother and infant. Besides, the study design did not permit to assess the effect of any antibiotic or other measures used to treat prior preterm labor or any UGI in underestimation of neonatal infection.

\section{Conclusion}

The prevalence of neonatal infection in the study was very high (37\%). In case of failure to delay preterm labor, birth weight $<2500 \mathrm{~g}$ and maternal UGI were found to enhance the risk by 3 to 4 times. Prior preterm labor should be systematically searched among delivering women and regarded as a potent risk factor to permit proper anti-infectious measures.

\section{Conflict of Interest}

None.

\section{Contribution of the Authors}

TUB generated the idea, designed the study and drafted the manuscript. KTD collected the data, participated in the analysis of results and participated in drafting the manuscript. The work was presented by KTD in April 2015 as a partial fulfillment of the completion of the graduation in medicine.

\section{References}

[1] Romero, R., Espinoza, J., Mazor, M. and Chaiworapongsa, T. (2004) The Preterm Parturition Syndrome. In: Critchely, 
H., Bennett, P. and Thornton, S., Eds., Preterm Birth, RCOG Press, London, 28-60.

[2] Romero, R., Espinoza, J., Kusanovic, J., Gotsch, F., Hassan, S., Erez, O., et al. (2006) The Preterm Parturition Syndrome. British Journal of Obstetrics and Gynaecology, 113, 17-42. http://dx.doi.org/10.1111/j.1471-0528.2006.01120.x

[3] Hitti, J., Tarcy-Hormoch, P., Murphy, J., Hillier, S.L., Aura, J. and Eschenbach, D.A. (2001) Amniotic Fluid Infection, Infants at 34 Weeks Gestation or Less. Obstetrics and Gynecology, 98, 1080-1088. http://dx.doi.org/10.1016/S0029-7844(01)01567-8

[4] Lee, S.Y., Park, K.H., Jeong, E.H., Oh, K.J., Ryu, A. and Park, K.U. (2012) Relationship between Maternal Serum C-Reactive Protein, Funisitis and Early-Onset Neonatal Sepsis. Journal of Korean Medical Sciences, 27, 674-680. http://dx.doi.org/10.3346/jkms.2012.27.6.674

[5] Sorokin, Y., Romero, R., Mele, L., Wapner, R.J., Iams, J.D., Dudley, D.J., et al. (2010) Maternal Serum Interleukin-6, C-Reactive Protein, and Matrix Metalloproteinase-9 Concentrations as Risk Factors for Preterm Birth $<32$ Weeks and Adverse Neonatal Outcomes. American Journal of Perinatology, 27, 631-640. http://dx.doi.org/10.1055/s-0030-1249366

[6] Huras, H., Ossowski, P., Jach, R. and Reron, A. (2011) Usefulness of Marking Alkaline Phosphatase and C-Reactive Protein in Monitoring the Risk of Preterm Delivery. Medical Sciences Monitoring, 17, 657-662. http://dx.doi.org/10.12659/msm.882052

[7] Gotsch, F., Romero, R., Kusanovic, J.P., Mazaki-Tovi, S., Pineles, B.L., Erez, O., et al. (2007) The Fetal Inflammatory Response Syndrome. Clinical Obstetrics and Gynecology, 50, 652-683. http://dx.doi.org/10.1097/GRF.0b013e31811ebef6

[8] Mukhopadhyay, S. and Puopolo, K.M. (2012) Risk Assessment in Neonatal Early-Onset Sepsis. Seminars in Perinatology, 36, 408-415. http://dx.doi.org/10.1053/j.semperi.2012.06.002

[9] Puopolo, K.M., Draper, D., Wi, S., Newman, T.B., Zupancic, J., Lieberman, E., Smith, M. and Escobar, G.J. (2011) Estimating the Probability of Neonatal Early-Onset Infection on the Basis of Maternal Risk Factors. Pediatrics, 128, e1155-e1163.

[10] Baltimore, R.S. (2003) Neonatal Sepsis. Epidemiology and Management. Pediatric Drugs, 5, 723-740.

[11] Seo, K., McGregor, J.A. and French, J.I. (1992) Preterm Birth Is Associated with Increased Risk of Maternal and Neonatal Infection. Obstetrics and Gynecology, 79, 75-80.

[12] Chan, G.J., Lee, A.C.C., Baqui, A.H., Tan, J. and Black, R.E. (2015) Prevalence of Early-Onset Neonatal Infection among Newborns of Mothers with Bacterial Infection or Colonization: A Systematic Review and Meta-Analysis. BMC Infectious Diseases, 15, 118. http://dx.doi.org/10.1186/s12879-015-0813-3

[13] Seale, A.C., Blencowe, H., Manu, A.A., Nair, H., Bahl, R., Shamim Qazi, S.A., Zaidi, A.K., Berkley, J.A., Cousens, S.N. and Lawn, J.E., for the pSBI Investigator Group (2014) Estimates of Possible Severe Bacterial Infection in Neonates in Sub-Saharan Africa, South Asia, and Latin America for 2012: A Systematic Review and Meta-Analysis. Lancet Infectious Diseases, 14, 731-741. http://dx.doi.org/10.1016/S1473-3099(14)70804-7

[14] Zaretsky, M.V., Alexander, J.M., Byrd, W. and Bawdon, R.E. (2004) Transfer of Inflammatory Cytokines across the Placenta. Obstetrics \& Gynecology, 103, 546-550. http://dx.doi.org/10.1097/01.AOG.0000114980.40445.83

[15] Tandu-Umba, B., Mbangama, M.A., Kamongola, K.M.B., Kamgang, T.A.G., Kivuidi, M.P., Kasonga, M.S., et al. (2014) Pre-Pregnancy High-Risk Factors at Booking: How Predictive Are These of Pregnancy Outcomes? International Journal of Women's Health, 6, 1011-1018. http://dx.doi.org/10.2147/IJWH.S69230

[16] Tandu-Umba, B. And Mbangama, M.A. (2015) Association of Maternal Anemia with Other Risk Factors in Occurrence of Great Obstetrical Syndromes at University Clinics, Kinshasa, DR Congo. BMC Pregnancy and Childbirth, 15, 183. http://dx.doi.org/10.1186/s12884-015-0623-z

[17] Bellad, M.B., Dhumale, H. and Shravage, J.C. (2009) Preterm Labor: A Review. South Asian Federation of Obstetrics and Gynecology, 1, 1-4. http://dx.doi.org/10.5005/jp-journals-10006-1001 